\title{
Follow-up Care of Monoclonal Gammopathy of Undetermined Significance: A Guide for Primary Care Physicians
}

Hammad Z*, Hernandez E and Tate S

Humanities, Health and Society, Herbert Wertheim

College of Medicine, Florida International University, Miami, USA

*Corresponding author: Zeidan Hammad, Humanities, Health and Society, Herbert Wertheim College of Medicine, Florida International University, Miami, USA

Received: May 28, 2021; Accepted: June 24, 2021; Published: July 01, 2021

\section{Introduction}

Monoclonal Gammopathy of Undetermined Significance (MGUS) is a condition in which M protein, an abnormal monoclonal immunoglobulin, is present in the blood at a nonmalignant level. Specifically, it is defined by: blood serum $M$ protein concentration $<3 \mathrm{~g} / \mathrm{dL}(<30 \mathrm{~g} / \mathrm{L}),<10 \%$ plasma cells in the bone marrow, and no evidence of end organ damage [1,2]. Evidence of end organ damage includes hypercalcemia, renal insufficiency, anemia, and bone lesions. These are indicative of MGUS progression and which can be attributed to the monoclonal plasma cell proliferative process [3]. MGUS occurs in $3 \%$ of the general population older than 50 years. Incidence increases with age and varies with sex with higher rates observered in males than females $[1,4]$.

MGUS is the most common plasma cell disorder, with $60 \%$ of patients that present to the Mayo Clinic with a monoclonal gammopathy being diagnosed with MGUS [3]. While it is typically an asymptomatic condition, it is premalignant disorder to other monoclonal gammopathies. Multiple Myeloma (MM) is almost always preceded by MGUS and the majority of patients will have detectable levels of $\mathrm{M}$ protein for at least 5 years prior to MM diagnosis $[5,6]$. MGUS also precedes immunoglobulin light chain (AL) amyloidosis and Waldenstrom Macroglobulinemia (WM) and tends to progress to disorders at a fixed but unrelenting rate of $1 \%$ per year [4].

\section{Discussion of M Protein}

M protein is produced by proliferation of cells in the B-lymphocyte lineage [1]. It can exist as a complete immunoglobulin with 2 heavy chains and 2 light chains or as a free light chain. M protein can also be categorized as $\operatorname{IgM}$ or non-IgM as differing cellular origin will produce IgM, IgG, or IgA variants. IgM MGUS is more likely to progress to lymphoma or WM, while non-IgM MGUS is more likely to progress to $\mathrm{MM}$ or $\mathrm{AL}[7]$.

Typically, $\mathrm{M}$ protein is an incidental finding during work up for another complaint. Routine screening for an $\mathrm{M}$ protein in the absence of clinical suspicion is not recommended due to the low risk of malignant progression. However, once it is found, a comprehensive history, Physical Examination (PE), and laboratory tests (serum protein electrophoresis, serum immunofixation, serum free light chains, $\mathrm{CBC}$, and serum calcium and creatinine) should be performed [8]. Serum protein electrophoresis will quantify substantial M protein concentrations, while serum immunofixation and serum free lightchain assay will detect lower levels of $\mathrm{M}$ protein and light chain M protein respectively. All 3 tests used together will give you $98 \%$ sensitivity for detection of serum m-protein [9].

At diagnosis, the presence of $\mathrm{MM}, \mathrm{WM}, \mathrm{AL}$ amyloidosis, and other MGUS-related disorders have to be excluded. In cases of significant proteinuria or renal insufficiency, kidney biopsy may be indicated [10]. After MGUS is confirmed, the patient should be risk stratified to determine the need for bone marrow biopsy and to predict the risk of progression [8].

\section{Initial Follow-up: Risk Stratification}

Previous studies [11,12] (A, B) have recognized subsets of patients with MGUS have different risks of progression to myeloma and other related disorders. Risk factors predicting progression are:

- $\quad$ Presence of non-IgG type M protein

- $\quad$ M protein concentrations $>1.5 \mathrm{~g} / \mathrm{dL}$

- An abnormal free light-chain ratio

Based on these, MGUS can be classified into 4 risk categories: low, low intermediate, high intermediate, and high.

- Low risk: All 3 risk factors are absent

- Low intermediate: 1 risk factor present

- High intermediate: 2 risk factors present

- High risk: All 3 risk factors present

A patient classified as high risk using these criteria will have a 10 -fold increase in risk of developing MM compared to a low risk patient. Half of patients with MGUS fall into the low-risk category, defined by IgG-type serum M protein in a concentration $<1.5 \mathrm{~g} / \mathrm{dL}$ and a normal serum free light chain ratio (kappa-lambda 0.26-1.65) [8].

\section{Long Term Follow-up}

Most recommendations regarding follow-up are based on expert opinion due to the lack of randomized data. Most experts agree that all patients should be re-evaluated six months after the $\mathrm{M}$ protein is detected, along with the following tests: $\mathrm{CBC}$, serum creatinine, serum calcium, serum protein electrophoresis, and serum free light 
chains [8].

Patients with low risk MGUS have a risk of progression of $5 \%$ in 20 years [13]. Low-risk patients with a stable M protein level who do not display clinical or laboratory evidence of myeloma or other disorders can be followed-up by Primary Care Providers (PCPs). After the six month reevaluation, they can be seen every two-three years [8]. These patients may be followed with history and PE, and repeating $\mathrm{CBC}$, calcium, creatinine, and measurement of serum and urine M-protein [13]. All other patients (non-low risk and lightchain MGUS) should be followed at annual intervals with a history and $\mathrm{PE}, \mathrm{CBC}$, serum calcium and creatinine, and serum and urinary M-protein measurements [13].

Follow up visits should also include monitoring for myelomadefining events. CRAB is helpful mnemonic for these events which include Calcium elevation ( $>1 \mathrm{mg} / \mathrm{dL}$ ), Renal insufficiency (creatinine $>2 \mathrm{mg} / \mathrm{dL}$ or creatinine clearance $<40 \mathrm{~mL} / \mathrm{min}$ ), Anemia (hemoglobin $<10 \mathrm{~g} / \mathrm{dL}$ ), and Bone lesions [14,15]. Elevation of serum M protein level above $3 \mathrm{~g} / \mathrm{dL}$ and/or between $10 \%$ and $60 \%$ clonal plasma cells in the marrow with no end organ damage would indicate progression of MGUS to Smoldering Multiple Myeloma (SMM) [16] SMM carries a significantly higher risk of progression to MM with $10 \%$ chance of malignancy annually for the first 5 years (51\% rate of progression to $\mathrm{MM}$ or $\mathrm{AL}$ ) [17]. Evidence of kidney dysfunction is concerning for progression Monoclonal Gammopathy of Renal Significance (MGRS). M protein can build up in the kidneys and eventually develop into deposits. Monoclonal protein deposits in the kidneys can be clinically indicated by increased protein or creatine levels and indicate progression to MGRS $[8,18]$.

No follow-up may also be considered in elderly patients or patients with significant comorbidity with a short life expectancy ( $<5$ years). These patients may only need laboratory investigations or bone marrow analysis only when symptoms suggestive of MM or related diseases develop [10].

A retrospective analysis of MGUS patients at Mayo Clinic $(\mathrm{H})$ found that optimally followed (follow up visits at least every 24 +/- 12 months) of MGUS patients only led to diagnosis of MM before symptoms or significant complications in $16 \%$ of patients. However, an additional 25\% of diagnoses before serious MM related complications came from workup of patient complaints. PCPs must constantly assess for and educate patients to report worrying symptoms (e.g. fatigue, neuropathy, weight loss, night sweats, and bone pain). This education is essential for early diagnosis of MGUS progression since these symptoms may present between followup visits [8,19]. Additionally, PCPs should be alert for signs and symptoms of $\mathrm{AL}$ amyloidosis such as restrictive cardiomyopathy, nephrotic range proteinuria, and hepatosplenomegaly [13].

Patients with MGUS have a decreased life expectancy and an increased risk of fractures, renal impairment (as seen in MGRS), cardiovascular disease, peripheral neuropathy, and recurrent infections $[20,21]$. Therefore, it may be appropriate to evaluate patients for excessive bone loss by using Dual-energy X-ray Absorptiometry (DXA), especially if other risk factors for osteoporosis are present Patients with low bone mineral density or prevalent fractures can receive treatment with bisphosphonates, and also calcium and vitamin D supplementation if dietary intake is insufficient [10]. While the link between MGUS and neuropathy is not entirely clear, IgM MGUS is most associated with demyelinating peripheral neuropathy and non-IgM MGUS is implicated in POEMS syndrome [22].

\section{Referral to Specialists}

Patients with intermediate and high-risk MGUS, abnormal serum free light-chain ratios, and those who show evidence of malignant progression should be referred to a hematologist. Patients with intermediate and high-risk MGUS could be referred for bone marrow biopsy before assessment by the hematologist. Additionally, if $\mathrm{AL}$ amyloidosis, WM or another $\mathrm{M}$ protein related disorder is suspected, referral to subspecialists is advised [8]. Any signs of renal insufficiency or proteinuria should prompt follow up with nephrologist for kidney biopsy to rule out MGRS $[8,18]$. MGUS patients with new cardiovascular or neurological complaints should also be referred to specialist for further evaluation and testing [21]. It is important to note that a recent study has found that levels of $\mathrm{M}$ proteins and the other markers may change over time, and thus it is important to reassess the patient's risk at each visit and refer accordingly [23].

\section{Conclusion}

MGUS is a premalignant condition with a steady rate of progression to multiple myeloma at a rate of $1 \%$ per year. Appropriate follow-up by PCPs can help mitigate superfluous healthcare spending while maintaining patient health and safety. All patients diagnosed with MGUS should be seen six months later. Following that, low risk patients should be seen every two-three years and all others should be seen annually. Educating the patient on worrying symptoms including fatigue, neuropathy, weight loss, night sweats, and bone pain is crucial to early detection of MGUS progression. Important tests to order at each visit are $\mathrm{CBC}$, serum creatinine, serum calcium, serum protein electrophoresis, and serum free light chains. It is important to refer non-low risk patients to a hematologist and continue to reassess the patient's risk at every visit.

\section{References}

1. Glavey SV, Leung N. Monoclonal gammopathy: The good, the bad and the ugly. Blood Rev. 2016; 30: 223-231.

2. Bird, Jenny, et al. "UK Myeloma Forum (UKMF) and Nordic Myeloma Study Group (NMSG): guidelines for the investigation of newly detected $\mathrm{M}$ proteins and the management of monoclonal gammopathy of undetermined significance (MGUS)." British journal of hematology. 2009; 147: 22-42.

3. Therneau TM, Kyle RA, Melton LJ, et al. Incidence of Monoclonal Gammopathy of Undetermined Significance and Estimation of Duration before First Clinical Recognition. Mayo Clin Proc. 2012; 87: 1071-1079.

4. Kyle RA, Therneau TM, Rajkumar SV, Larson DR, Plevak MF, Offord JR et al. Prevalence of monoclonal gammopathy of undetermined significance. New England Journal of Medicine. 2006; 354: 1362-1369.

5. Landgren O, Kyle RA, Pfeiffer RM, Katzmann JA, Caporaso NE, Hayes $\mathrm{RB}$, et al. Monoclonal gammopathy of undetermined significance (MGUS) consistently precedes multiple myeloma: a prospective study. Blood. 2009; 113: $5412-5417$

6. Weiss BM, Abadie J, Verma P, Howard RS, Kuehl WM. A monoclona gammopathy precedes multiple myeloma in most patients. Blood. 2009; 113: 5418-5422.

7. Kyle RA, Therneau TM, Rajkumar SV, Remstein ED, Offord JR, Larson DR et al. Long-term follow-up of IgM monoclonal gammopathy of undetermined significance. Blood. 2003; 102: 3759-3764. 
8. Khouri J, Samaras C, Valent J, et al. Monoclonal gammopathy of undetermined significance: A primary care guide. Cleve Clin J Med. 2019; 86: 39-46.

9. Kyle RA, Gertz MA, Witzig TE, Lust JA, Lacy MQ, Dispenzieri A, et al. Review of 1027 patients with newly diagnosed multiple myeloma. In Mayo Clinic Proceedings. 2003; 78: 21-33

10. van de Donk NWCJ, Palumbo A, Johnsen HE, et al. The clinical relevance and management of monoclonal gammopathy of undetermined significance and related disorders: recommendations from the European Myeloma Network. Haematologica. 2014; 99: 984-996.

11. Rajkumar SV, Kyle RA, Therneau TM, Melton LJ, $3^{\text {rd }}$, Bradwell AR, Clark RJ, et al. Serum free light chain ratio is an independent risk factor for progression in monoclonal gammopathy of undetermined significance. Blood. 2005; 106 812-817.

12. Katzmann JA, Clark R, Kyle RA, Larson DR, Therneau TM, Melton L, et al Suppression of uninvolved immunoglobulins defined by heavy/light chain pai suppression is a risk factor for progression of MGUS. Leukemia. 2003; 27 208-212.

13. Willrich MAV, Murray DL, Kyle RA. Laboratory testing for monoclona gammopathies: Focus on monoclonal gammopathy of undetermined significance and smoldering multiple myeloma. Clin Biochem. 2018; 51: 38 47.

14. Dimopoulos M, Kyle R, Fermand JP, Rajkumar SV, San Miguel J, ChananKhan A \& International Myeloma Workshop Consensus Panel 3. Consensus recommendations for standard investigative workup: report of the International Myeloma Workshop Consensus Panel 3. Blood, The Journal of the American Society of Hematology. 2011; 117: 4701-4705

15. Rajkumar SV, Dimopoulos MA, Palumbo A, Blade J, Merlini G, Mateos MV, et al. International Myeloma Working Group updated criteria for the diagnosis of multiple myeloma. The lancet oncology. 2014; 15: e538-e548.
16. Rajkumar SV, Landgren O, Mateos MV. Smoldering multiple myeloma Blood. 2015; 125: 3069-3075.

17. Kyle RA, Remstein ED, Therneau TM, Dispenzieri A, Kurtin PJ, Hodnefield $\mathrm{JM}$, et al. Clinical course and prognosis of smoldering (asymptomatic) multiple myeloma. New England Journal of Medicine. 2017; 356: 2582-2590.

18. Leung N, Bridoux F, Hutchison CA, Nasr SH, Cockwell P, Fermand JP, et al. Monoclonal gammopathy of renal significance: when MGUS is no longer undetermined or insignificant. Blood. The Journal of the American Society of Hematology. 2012; 120: 4292-4295.

19. Bianchi G, Kyle RA, Colby CL, Larson DR, Kumar S, Katzmann JA, et al. Impact of optimal follow-up of monoclonal gammopathy of undetermined significance on early diagnosis and prevention of myeloma-related complications. Blood. The Journal of the American Society of Hematology. 2010; 116: 2019-2025.

20. Kyle RA, Larson DR, Therneau TM, Dispenzieri A, Kumar S, Cerhan JR, et al. Long-term follow-up of monoclonal gammopathy of undetermined significance. New England Journal of Medicine. 2018; 378: 241-249.

21. Lomas OC, Mouhieddine TH, Tahri S, Ghobrial IM. Monoclonal Gammopathy of Undetermined Significance (MGUS)-Not So Asymptomatic after All. Cancers. 2020; 12: 1554.

22. Ramchandren S, Lewis RA. Monoclonal gammopathy and neuropathy. Current opinion in neurology. 2009; 22: 480-485

23. Landgren O, Hofmann JN, McShane CM, et al. Association of Immune Marker Changes With Progression of Monoclonal Gammopathy of Undetermined Significance to Multiple Myeloma. JAMA Oncol. 2019. 